\title{
RÉGIMEN JURÍDICO DEL DISTINTIVO DE CALIDAD EN LA PRODUCCIÓN AGRARIA
}

\author{
ÁNGEL SÁNCHEZ HERNÁNDEZ \\ Doctor en Derecho \\ Profesor Titular E.U. de Derecho Civil \\ Universidad de La Rioja
}

\section{SUMARIO}

I - InTROduCción. II - El Reglamento CEE 2081/92, DEl CONSEJo DE 14 DE JULIO DE 1992 RELATIVO A LA PROTECCIÓN DE LAS INDICACIONES GEOGRÁFICAS Y DE LAS DENOMINACIONES DE ORIGEN DE LOS PRODUCTOS AGRÍCOLAS Y ALIMENTICIOS. II.1. Ámbito de aplicación. II.2. Concepto de Denominación de Origen Protegida. II.3. Concepto de Indicación Geográfica Protegida. II.4. Diferencias entre Denominación de Origen Protegida e Indicación Geográfica Protegida. II.5. Qué garantiza una Denominación de calidad con nombre geográfico (D.O.P. o I.G.P.) II.6. Efectos jurídicos como consecuencia del registro de denominaciones de calidad con nombre geográfico. II.7. El logotipo de los productos registrados bajo la categoría de Denominación de Origen Protegida e indicación Geográfica Protegida. III - EL REGLAMENTO CEE 2082/92 DE CERTIFICACIONES DE ESPECIFICIDAD DE LOS PRODUCTOS AGRARIOS Y ALIMENTARIOS. III.1.-Diferencia entre certificación de especificidad y las denominaciones de origen e indicaciones geográficas protegidas. III.2. Las marcas de calidad en la Comunidad Autónoma de La Rioja. IV- LA AGRICULTURA ECOLÓGICA COMO PRODUCCIÓN AGRARIA DE CALIDAD. IV.1.Significado de la agricultura ecológica. IV.2. Reglamento CEE $n^{\circ}$ 2092/91 del Consejo, sobre producción agrícola ecológica y su indicación en los productos agrarios y alimentarios ${ }^{1}$. IV.2.1.- Ámbito de aplicación. IV.2.2.- Normas relativas a la producción ecológica. IV.2.2.1. Vegetal. IV.2.2.2.Animal. IV.2.3. Normas relativas a la transformación de los productos agrícolas ecológicos en

${ }^{1}$ Fue completado por Reglamento CEE 1084/1999 de 24 de agosto de 1999 
alimentos. IV.2.4. Normas relativas al etiquetado y a la publicidad. IV.2.5. El logotipo de los productos agrícolas ecológicos. IV.2.6. Medidas de Control. IV.3. La producción ecológica en la Comunidad Autónoma de La Rioja. IV.3.1. Decreto 56/2000, de 17 de noviembre, de la Consejería de Agricultura, Ganadería y Desarrollo Rural, sobre producción agrícola ecológica e indicación de la misma en los productos agrarios y alimentarios y se crea el Consejo de Producción Agraria Ecológica de la Rioja. IV.3. 2. La agricultura y ganadería ecológica de La Rioja en cifras.

\section{RESUMEN}

El consumidor demanda productos agrarios de calidad y al mismo tiempo que saludables, satisfagan el paladar. Esa exigencia de calidad de los consumidores por los productos alimentarios depende de la garantía de obtenerlos sometidos controles rigurosos. La promoción de la calidad en la producción agraria fue recogida por la Unión Europea, en disposiciones referidas a productos agrarios distintos del vino: los Reglamentos comunitarios $\mathrm{n}^{\circ} 2081 / 92$ relativo a la protección de las indicaciones geográficas y de las denominaciones de origen de los productos agrícolas y alimenticios y $\mathrm{n}^{\circ}$. 2082/92 de certificaciones de especificidad de los productos agrarios y alimentarios.

\section{INTRODUCCIÓN}

El consumidor demanda productos agrarios de calidad y al mismo tiempo que saludables, satisfagan el paladar. Esa exigencia de calidad se manifiesta en que el interés de los consumidores por los productos alimentarios depende de la garantía de obtenerlos sometidos controles rigurosos.

En España existen antecedentes en la promoción de la calidad en la producción agraria. Aunque en este trabajo, no me ocupo del vino, por tener su propia legislación especial, si destacaré como la Ley 25/1970, de 2 de diciembre, del vino, viñas y alcoholes, concretamente en su disposición adicional quinta autorizaba al gobierno "para que, previa propuesta del FORPA o de la organización sindical, según proceda, pueda hacer extensivo lo establecido en los artículos 95 y siguientes de esta Ley a aquellos productos agrarios cuya protección de calidad tenga especial interés económico o social".

Por otra parte, desde la óptica del productor, la calidad de la producción agraria, es un factor de desarrollo del mundo rural al obtener los productores mayores ingresos como contrapartida del esfuerzo cualitativo que realizan en alcanzar esa calidad en los productos agrarios. 
Ahora bien la promoción de la calidad en la producción agraria unida como alternativa al desarrollo rural fue recogida por los Ministros de agricultura de la Unión Europea, quienes en 1989, durante un Consejo informal celebrado en Salamanca, tienen la idea de dictas disposiciones comunitarias sobre el particular referidas a productos agrarios distintos del vino - que ya contaba entonces con normativa propia: el vino con un Reglamento comunitario de 1970 y los licores con normativa de ese mismo año 1989 -. Surgen así los Reglamentos comunitarios 2081/92 y 2082/92.

\section{EL REGLAMENTO CEE 2081/92, DEL CONSEJO DE 14 DE JULIO DE 1992 RELATIVO A LA PROTECCION DE LAS INDICACIONES GEOGRAFICAS Y DE LAS DENOMINACIONES DE ORIGEN DE LOS PRODUCTOS AGRICOLAS Y ALIMENTICIOS.}

Este reglamento se aplica a " productos agrarios " que tengan una relación entre sus características y su origen geográfico. Para ello establece dos sistemas de valoración y protección de las denominaciones geográficas: la Indicación Geográfica Protegida (IGP) y la Denominación de Origen Protegida (DOP).

Para llevar estas referencias geográficas los productos agrarios deben cumplir ciertas condiciones: las establecidas en los denominados pliegos de condiciones. $\mathrm{Su}$ cumplimiento permite inscribir las IGP y las DOP en un registro comunitario.

\section{II.1. ÁMBITO DE APLICACIÓN}

En su artículo primero ${ }^{2}$ el Reglamento 2081/92 establece normas relativas a la producción de DOP e IGP de "productos agrícolas destinados a la alimentación humana", pero no de todos, sólo de los contemplados en el Anexo II del Tratado de la CEE y en los Anexos I y II del Reglamento 2081/92.

A modo de ejemplo, dentro de los productos que presentan características que les relacionen con su medio natural y las condiciones de cultivo y elaboración y que admiten acogida a una DOP e IGP, citaremos quesos, frutas y verduras, encurtidos vegetales, productos de carne fresca, materias grasas -aceites de oliva virgen-, derivados de la carne -jamones ${ }^{3}$, embutidos curados, salazones cárnicas-, arroz, legumbres secas, pimientos, espárragos, cerveza , miel , turrón productos de panadería, repostería o galletería ...

No se aplica el Reglamento a los productos del sector vitivinícola ni a las bebidas espirituosas, para así, evitar la problemática del sector vitivinícola que aparte de contar con tradición histórica, es más difícil. No obstante esta exclusión, en la aplicación del Reglamento 2081/92 recibe la influencia de principios que traen precedentes del sector vitivinícola.

\footnotetext{
${ }^{2}$ Vide el artículo primero del reglamento (CEE) no 2081/92 del Consejo de 14 de julio de 1992 relativo a la protección de las indicaciones geográficas y de las denominaciones de origen de los productos agrícolas y alimenticios.

${ }^{3}$ Vide al respecto el real Decreto 1083/2001, de 5 de octubre, por el que se aprueba la norma de calidad para el jamón ibérico, paleta ibérica y caña de lomo ibérico elaborados en España, BOE $n^{\circ} 247$, del lunes 15 de octubre de 2001.
} 


\section{II.2. ConcEPTo de DENOMINACIÓN DE ORIGEN PROTEGIDA.}

El artículo segundo del reglamento ${ }^{4}$ entiende por Denominación de Origen el nombre de una región, de un lugar determinado, o de un país, que sirve para designar un "producto agrícola o un producto alimenticio" -originario de ese lugar- cuyas características se deben fundamentalmente o exclusivamente al medio geográfico con sus factores naturales y humanos, y cuya producción, transformación y elaboración se realizan en la zona geográfica determinada.

Por lo tanto, lo determinante en la Denominación de Origen son los factores naturales y humanos de la zona de producción, esto es, la existencia de un vínculo entre las características del producto y la zona de producción, transformación y elaboración.

En suma, un producto con Denominación de Origen Protegida lleva un nombre geográfico, no por producirse en un determinado territorio, sino por tener unas características intrínsecas que están vinculadas a la zona ${ }^{5}$.

También se consideran asimismo Denominaciones de Origen algunas "denominaciones tradicionales" - geográficas o no- que designen un producto agrícola alimentario originario de una región o lugar determinado y que cumplen las características exigidas para la Denominación de Origen ${ }^{6}$.

\section{II.3. CONCEPTO DE INDICACIÓN GEOGRÁFICA PROTEGIDA}

Por tal se entiende, el nombre de una región, lugar determinado o un país que sirve para designar un producto "agrícola o alimentario" originario de dicho lugar, y posee una calidad determinada, una reputación u otra característica que pueda atribuirse

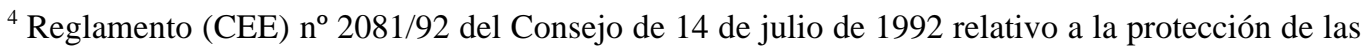
indicaciones geográficas y de las denominaciones de origen de los productos agrícolas y alimenticios.

${ }^{5}$ Dos ejemplos de Denominaciones de Origen Protegida:

$1^{\circ}$ - Jamones de la D. O Dehesa de Extremadura. Los ibéricos son una primitiva raza autóctona de cerdos de origen mediterráneo especialmente dotados para aprovechar directamente, a diente, los recursos de las dehesas de encinas y alcornoques. Entre las cualidades de esta primitiva raza destaca su capacidad para acumular grasa bajo la piel o infiltrar ésta en sus músculos, lo que caracteriza y hace exclusivos los productos derivados del ibérico. Don son las peculiaridades que caracterizan al ibérico respecto al sistema de producción industrial de cerdos blancos: a) Régimen extensivo- los ibéricos se crían libres en el campo (la dehesa), opuesto al régimen intensivo de cría y cebo de cerdos, en el que los animales permanecen confinados con alimentación forzada. b)Mientras el cerdo industrial se sacrifica a los seis meses, el sacrificio de los ibéricos con destino a producción de curados es de 14 meses.

$2^{\circ}$ - Queso gallego de Tetilla (Orden de la Consellería 18-6-1993, Orden Ministerial de 24- 111994, Reglamento CE 1107/96 de la Comisión 17-6-1996.). Se trata de un queso de leche de vaca de pasta blando y corteza lavada, con un periodo de maduración mínimo de 7 días. La elaboración y maduración debe efectuarse en instalaciones del territorio de Galicia. La leche procede de ganado saneado de raza frisona, pardo alpina y rubia gallega. La pasta es blanca, cremosa y uniforme con pocos ojos repartidos regularmente, de color blanco- marfil amarillento. Corteza fina y elástica, amarilla y sin mohos.

${ }^{6}$ Artículo 2 apartado tercero del Reglamento (CEE) no 2081/92 del Consejo de 14 de julio de 1992 relativo a la protección de las indicaciones geográficas y de las denominaciones de origen de los productos agrícolas y alimenticios.
} 
a dicho origen geográfico y cuya producción y/ o transformación y/o elaboración se realicen en zona geográfica delimitada ${ }^{7}$.

\section{II.4. DifERENCIAS ENTRE DENOMINACIÓN DE ORIGEN PROTEGIDA E INDICACIÓN GEOGRÁFICA PROTEGIDA}

Mientras que en la Denominación de Origen establece un vínculo "muy estrecho" con la tierra - todo debe producirse, elaborarse y transformarse en la zona -, en cambio en la Indicación Geográfica protegida establece un vínculo "más frágil" pues basta con que la elaboración - no ya la producción o transformación- tenga lugar en la zona y exista una característica particular del producto que justifique su origen.

Para ver claramente esta diferencia pensemos en un supuesto Indicación Geográfica Protegida: la sobrasada mallorquina. Se fabrica en Mallorca con productos extraídos del cerdo, pero no todos los lechones son de Mallorca. Si estuviésemos ante un producto con Denominación de Origen todo debería proceder de la zona.

\section{II.5. QUÉ GARANTIZA UNA DENOMINACIÓN DE CALIDAD CON NOMBRE GEOGRÁFICO (D.O.P. O I.G.P.)}

Es claro que el origen geográfico, por si mismo exclusivamente, no determina la calidad: un producto no lleva un nombre geográfico por generarse en dicho territorio, sino por tener características vinculadas a la zona.

Las denominaciones de calidad con nombre geográfico deben basarse exclusivamente en las características intrínsecas de los productos amparados . En este sentido, estas denominaciones de calidad pretenden proteger de imitaciones aquellos productos reconocidos por su lugar de procedencia, dada la influencia del medio geográfico en las características intrínsecas del producto, o en su reputación. Esa protección se realiza:

a) reconociendo y respaldando "algo notorio" que ya tiene el producto -la calidad ligada al medio natural y a los factores humanos-.

7 Vide el artículo 2.2.b del Reglamento (CEE) n ${ }^{\circ}$ 2081/92 del Consejo de 14 de julio de 1992 relativo a la protección de las indicaciones geográficas y de las denominaciones de origen de los productos agrícolas y alimenticios.

Como ejemplos de Indicación Geográfica Protegida señalaré dos: $1^{\circ}$ - Lechazo de Castilla y León: la cuenca hidrográfica del Duero , hasta una altitud de 1000 metros es el área geográfica de producción de corderos lechales. Desde tiempos inmemoriales se vienen criando ovejas de zonas autóctonas - castellana, charra y ojalada - que son las únicas capaces de criar cordero lechal, entendiendo por tal la cría de oveja, que todavía mama y cuyas características son el color blanquecino rosado de la carne, olor poco intenso - ni a lana ni a sebo -, peso vivo máximo al sacrificio $12 \mathrm{~kg}$. En 35 días y peso en canal de 4,5 a $7 \mathrm{~kg}$.

$2^{\circ}$-Judías del Barco de Ávila (Orden del ministerio de Agricultura de 27-7-1984) : La comarca del Barco - Piedrahita (Ávila) es un valle que por su orografía discontinua, permite el cultivo en terrazas de legumbres protegidas del frío mesetario por las cadenas montañosas. Los suelos, formados a partir de materiales graníticos, ligeros y bien constituidos, con bajo contenido de carbonato cálcico y excelentes condiciones físicas de permeabilidad y aireación, unido a la calidad de las aguas permite obtener judías excelentes. 
b) apoyando institucionalmente esa denominación de calidad -avalando una calidad-, aval que refuerza la imagen del producto y transmite credibilidad a los consumidores ante los que aparece con un signo distintivo comercial de prestigio, aumentándose así la demanda ya existente de productos específicos y únicos ${ }^{8}$. Ahora bien, más allá de las motivaciones económicas , la protección obedece también a una exigencia cultural. Proteger la denominación de calidad es tanto como defender la identidad cultural, una historia que forma parte de la civilización europea.

\section{II.6. EFECTOS JURÍDICOS COMO CONSECUENCIA DEL REGISTRO DE DENOMINACIONES DE CALIDAD CON NOMBRE GEOGRÁFICO}

El efecto jurídico fundamental que resulta como consecuencia del Registro de denominaciones de calidad con nombre geográfico consiste en la reserva de denominación: "sólo los productores que se encuentran en la zona geográfica y que cumplan la normativa establecida tendrán derecho para utilizar la denominación protegida". Tales productores ostentan un Derecho exclusivo de utilización de las Denominaciones de Origen e Indicaciones Geográficas Protegidas, evitando la competencia desleal de los productos de imitación ${ }^{10}$.

Ahora bien, si bien los productores que cumplen las reglas establecidas tienen derecho a utilizar la denominación protegida, sin embargo el nombre de la denominación protegida se considera de titularidad pública para protegerlo y conservarlo contra su uso indebido. Nadie puede reservarse una denominación de calidad en cuanto que debe resultar accesible de pleno derecho a cualquier producto comunitario cuyos productos respondan intrínsecamente a los requisitos exigidos.

\section{II.7. EL LOGOTIPO DE LOS PRODUCTOS REGISTRADOS BAJO LA CATEGORÍA DE DENOMINACIÓN DE ORIGEN PRoteGIDA E INDICACIÓN GEOGRÁFICA PROTEGIDA}

La existencia de un logotipo de los productos registrados bajo la categoría de Denominación de Origen Protegida e indicación Geográfica Protegida tiene una doble finalidad. En primer lugar para que los consumidores puedan reconocer estos productos registrados. En segundo lugar, con el fin de que el productor se beneficie de un instrumento de marketing que identifica un producto con mayor valor intrínseco que el resto.

${ }^{8}$ Desde el punto de vista del comercio, el reglamento 2081/92, se revela, no únicamente como una reglamentación positiva de las DOP e IGP, sino también como un sistema único para justificar la imposición de restricciones o limitaciones al comercio de productos agrarios que se designen con nombre geográfico.

9 VITAL, F. , Desarrollo de las actividades de la comisión en el ámbito de las denominaciones de origen protegidas e indicaciones geográficas protegidas (Reglamento 2081/92) y de las certificaciones de características específicas (Reglamento 2082/92) de productos agrícolas y alimenticios, en "III Encuentros Europeos de denominaciones de Origen e Indicaciones Geográficas protegidas, Salical- Tecnosalical 1999, Gobierno de La Rioja, Logroño, 1999. Pp. 23 y ss.

${ }^{10}$ VENTURA, S., la política comunitaria en materia de signos oficiales de calidad de los productos agrícolas, en "III Encuentros Europeos de denominaciones de Origen e Indicaciones Geográficas protegidas, Salical- Tecnosalical 1999, Gobierno de La Rioja, Logroño, 1999, pp. 137 y ss. 


\section{III- EL REGLAMENTO CEE 2082/92 DE CERTIFICACIONES DE ESPECIFICIDAD DE LOS PRODUCTOS AGRARIOS Y ALIMENTARIOS}

En la línea de diversificación de la producción agraria, este reglamento 2082/92, trata de poner a disposición de los medios económicos instrumentos que permitan valorizar sus productos, así como de garantizar la protección del consumidor con mayor calidad y una mejor información sobre las características específicas de los productos agrarios que le permitan elegir con mayor conocimientos de causa.

Este reglamento introduce un sistema con un régimen voluntario que permite dar a conocer la calidad de un producto alimentario así como las garantías que justifiquen las referencias al mismo en el comercio.

La certificación comunitaria de características específicas se aplicaran - a tenor de lo preceptuado en el artículo 1.1.- por una parte a los concretos productos agrícolas Anexo II del Tratado de la CEE- destinados a la alimentación humana, y por otra parte a determinados productos alimentarios -Anexo del propio Reglamento 2082/92).

Para que un producto agrario alimenticio tenga una especialidad tradicional garantizada -ETG-, es preciso que se distinga de otros productos similares pertenecientes a la misma categoría, por contar con características específicas como haber sido producido a partir de materias primas tradicionales, o bien por presentar una composición tradicional o un modo de producción y/o transformación tradicional.

Salvo que así se disponga por la normativa específica de un producto, las características específicas no podrán limitarse a la composición cualitativa o cuantitativa o a un modo de producción definidos por la normativa.

Mediante el reconocimiento por la Unión Europea de las características específicas de un producto, se incluye el nombre del producto agrario y alimentario en el Registro de Certificaciones Características y Específicas ${ }^{11}$.

Los productos agrarios o alimentarios para figurar en ese Registro tienen que: haber sido producidos a partir de materias primas tradicionales, o bien presentan una composición tradicional o un modo de producción y/o transformación que pertenezca al tipo tradicional.

No cabe registrar -para la obtención de este tipo de certificación- un producto agrario o alimentario cuya única característica específica radique en su procedencia geográfica o sea únicamente resultado de la aplicación de una innovación tecnológica.

\section{III.1.-DIFERENCIA ENTRE CERTIFICACIÓN DE ESPECIFICIDAD Y LAS DENOMINACIONES DE ORIGEN E INDICACIONES GEOGRÁFICAS PROTEGIDAS}

En el caso de las denominaciones de origen e indicaciones geográficas protegidas, el origen del producto determina todas o algunas de sus características. Sin embargo, en los supuestos de las certificaciones de especialidad tradicional garantizada, los productos se distinguen, de otros de su misma categoría, bien por la naturaleza

${ }^{11}$ Artículos 2.3 y 3 del Reglamento(CEE) no 2082/92 del Consejo de 14 de julio de 1992,, relativo a la certificación de las características específicas de los productos agrícolas y alimenticios. 
especial de las materias primas empleadas, por la composición del producto acabado o bien por los métodos de producción o transformación tradicionales. En el etiquetado y en la publicidad, se pueden utilizar la mención de los "aspectos característicos" de los productos, pero sin poder establecer vinculo entre su origen y su calidad.

En las certificaciones de calidad, para no confundir al consumidor con las Denominaciones de Origen e Indicaciones Geográficas Protegidas, la mención a la procedencia sólo puede ser objeto de una simple indicación de la localización del organismo de calidad y/o control. En suma, las certificaciones de calidad no pueden establecer vinculo entre origen y calidad intrínseca del producto agrario -para eso están las Denominaciones de Origen Protegidas e Indicaciones Geográficas Protegidas-.

Así, la marca de calidad genérica tiene que estar abierta a todos los productores de la Unión Europea, siempre que cumplan los requisitos exigidos ${ }^{12}$, sin que pueda concederse para una región con un nombre geográfico, puesto que "las características específicas" que distinguen a los productos con esa marca de calidad genérica no están reservados a una zona geográfica.

La Comisión Europea sigue la evolución de la promoción y creación de "denominaciones regionales de calidad" para cerciorarse de que no obstaculizan la libre circulación de mercancías o la infracción veraz de los consumidores. Por su parte, el Tribunal de Justicia de la Unión Europea viene entendiendo que la utilización de denominaciones de calidad debe atenerse a los requisitos de libre accesibilidad, igualdad para todo producto comunitario y comprobación por organismo independiente; de otra forma se comprometería la libertad del comercio al implicar una restricción de las importaciones o exportaciones ${ }^{13}$.

\section{III.2. LAS MARCAS DE CALIDAD EN LA COMUNIDAD AUTÓNOMA DE LA RIOJA}

En el contexto del acervo normativo comunitario, la Comunidad Autónoma de La Rioja, aprueba, mediante Decreto 6/1999, de 19 de febrero, de la Consejería de Agricultura, Ganadería y Desarrollo Rural, el Reglamento que establece la Marca de Garantía "RC" para productos agrarios y agroalimentarios.

La titularidad de la marca de calidad "RC" -Registrado y Certificado- es la Comunidad Autónoma de la Rioja, correspondiéndole su gestión a la Consejería de Agricultura ${ }^{14}$. La autorización para usar esta marca "RC" se otorgará por la Consejería, previa acreditación de los requisitos establecidos en el reglamento de calidad, a los

\footnotetext{
${ }^{12}$ Ya el preámbulo del Reglamento(CEE) no 2082/92 del Consejo de 14 de julio de 1992, relativo a la certificación de las características específicas de los productos agrícolas y alimenticios, dice que "a fin de no crear condiciones de competencia desigual, cualquier productor debe poder utilizar bien un nombre registrado acompañado de una mención y, en su caso, de un símbolo comunitario, o bien un nombre registrado como tal, siempre y cuando el producto agrícola o alimenticio que produzca o transforme cumpla los requisitos de pliego de condiciones correspondiente y que el organismo de control que haya elegido esté autorizado".

${ }^{13}$-Vide artículos 6,30 y párrafo $2^{\circ}$ del apartado $3^{\circ}$ de su artículo 40 del Tratado CEE fundamento del razonamiento del Tribunal.

${ }^{14}$ Artículo 2 del Decreto 6/1999, de 19 de febrero, de la Consejería de Agricultura, Ganadería y Desarrollo Rural.
} 
productos que reúnan condiciones específicas de calidad en la producción, elaboración, composición e identificación del producto ${ }^{15}$.

Pueden solicitar el uso de la marca "RC", además de las entidades asociativas sin ánimo de lucro y que gestionen el uso autorizado de marca por sus asociados-, las personas físicas o jurídicas que produzcan, elaboren, transformen y comercialicen el producto para el que se pretenda la autorización, siempre y cuando justifiquen las características especiales del sector así como las singularidades del producto afectado ${ }^{16}$.

La vigencia de la autorización del uso de la marca, es de un año, renovable por periodos sucesivos de dos años cada uno . La Consejería de Agricultura, Ganadería y Desarrollo Rural, resolverá dejar sin efecto la renovación en caso de incumplimiento del régimen de autorización ${ }^{17}$.

Aparte del control de las asociaciones que gestionan la autorización del uso de la marca "RC", existen otros controles externos del uso de la marca de calidad - bien sea por la propia Consejería o por otras empresas independientes- ${ }^{18}$.

Existe un Registro para inscripción de productos agrarios y agroalimentarios, respecto de los que se haya autorizado el uso de la marca "RC"

Se crea un logotipo para ser reconocidos los productos con el distintivo de calidad "RC". Actualmente son quince los productos con ese distintivo autorizados por la Consejería de Agricultura del Gobierno de La Rioja: frutos y hortalizas frescas; conservas vegetales; productos deshidratados y congelados; productos cárnicos elaborados; miel; caramelos; galletas; embutidos de productos de la pesca y semiconservas de anchoas en salazón o en aceite; quesos; vinagres vínicos ; pacharán, aguardientes y otras bebidas derivadas de alcoholes naturales; fardelejos; platos preparados tradiciones ; mazapanes de soto; agua -mineral natural o mineral carbonatada- y café -envasado en grano o molido, ya sea natural, torrefacto o mezcla del ambos; también se ampara el café descafeinado-.

${ }^{15}$ Artículo 3 del Decreto 6/1999, de 19 de febrero, de la Consejería de Agricultura, Ganadería y Desarrollo Rural.

${ }^{16}$ Artículo 3 del Reglamento que establece la marca de garantía "RC" para productos agrarios y agroalimentarios aprobado por Decreto 6/1999, de 19 de febrero, de la Consejería de Agricultura, Ganadería y Desarrollo Rural.

${ }^{17}$ Artículo 5 del Reglamento que establece la marca de garantía "RC" para productos agrarios y agroalimentarios aprobado por Decreto 6/1999, de 19 de febrero, de la Consejería de Agricultura, Ganadería y Desarrollo Rural.

${ }^{18}$ Artículo 7 del Reglamento que establece la marca de garantía "RC” para productos agrarios y agroalimentarios aprobado por Decreto 6/1999, de 19 de febrero, de la Consejería de Agricultura, Ganadería y Desarrollo Rural.

${ }^{19}$ Artículo 9 del Reglamento que establece la marca de garantía "RC" para productos agrarios y agroalimentarios aprobado por Decreto 6/1999, de 19 de febrero, de la Consejería de Agricultura, Ganadería y Desarrollo Rural. 


\section{IV- LA AGRICULTURA ECOLOGICA COMO PRODUCCIÓN AGRARIA DE CALIDAD}

\section{IV.1.SIGNIFICADO DE LA AGRICULTURA ECOLÓGICA.}

La producción agraria ecológica tiene como objetivo primordial, además de buscar productos agropecuarios sanos elaborados con métodos que mantienen la integridad y las cualidades vitales del producto, la protección y preservación del medio ambiente, bien manteniendo la fertilidad del suelo a largo plazo, o reduciendo al mínimo el empleo de recursos no renovables, o bien, por último, reduciendo al mínimo la contaminación del agua, del suelo y aire derivados de prácticas agrícolas.

La agricultura ecológica entraña replantearse el modo de producción agraria: cultivar las tierras y criar el ganado de modo orgánico, sin ayuda de elementos químicos de síntesis.

Esta agricultura tiene como objetivo obtener alimentos de máxima calidad, sanos, respetando el medio ambiente y conservando la fertilidad de la tierra. Para ello resulta esencial, además del vínculo entre la agricultura y la naturaleza el respeto de los equilibrios naturales, que mantienen a la agricultura lejos de la intervención y del empleo de productos de síntesis.

En suma, la agricultura ecológica "es un sistema global de producción agrícola vegetales y animales- que prefiere el empleo de métodos de cultivo biológicos y mecánicos al de productos químicos sintéticos" ${ }^{20}$.

IV.2. REGLAMENTO CEE No 2092/91 DEL CONSEJO, SOBRE PRODUCCIÓN AGRÍCOLA ECOLÓGICA Y SU INDICACIÓN EN LOS PRODUCTOS AGRARIOS Y ALIMENTARIOS ${ }^{21}$

Inicialmente este Reglamento únicamente fijó normas para la producción ecológica de origen vegetal. En 1995, se contemplan dichas normas con la posibilidad de crear un logotipo para la agricultura ecológica y otras normas técnicas en relación con el etiquetado y el régimen de importación. En 1999 se aprueba el Reglamento CE 1084/1999, de 19 de julio, en el que se fijan las normas comunitarias relativas a la producción ecológica de origen animal. En marzo de 2000 se creó un logotipo comunitario para la agricultura ecológica.

El Reglamento CEE 2092/91 determina los requisitos que debe cumplir un producto agrícola o un alimento para llevar algún tipo de referencia al método de producción ecológica; define en qué consiste el método de obtención de productos vegetales y animales ecológicos: regula el etiquetado y la transformación, la inspección y el comercio de estros productos ecológicos en la Unión Europea así como la importación de productos ecológicos de terceros países.

${ }^{20}$ Vide directrices para la producción, elaboración, etiquetado y comercialización de alimentos producidos orgánicamente, aprobadas en junio de 1999 por la Comisión Codex alimentarius, de un programa mixto FAO/OMS, sobre los alimentos, al objeto de garantizar la seguridad alimentaria y lealtad de las transacciones comerciales en este ámbito.

${ }^{21}$ Fue completado por Reglamento CEE 1084/1999 de 24 de agosto de 1999 


\section{IV.2.1.- Ámbito de aplicación}

Se aplica a los productos vegetales y animales no transformados, a los productos agrícolas transformados destinados a la alimentación humana y a los piensos para animales, siempre que lleven en el etiquetado indicaciones para sugerir al consumidor que el producto se ha obtenido mediante el método de producción ecológica ${ }^{22}$. A los productos agrícolas ecológicos le son de aplicación las disposiciones generales por las que se regulan la producción, la elaboración, la comercialización, el etiquetado y el control de los productos agrícolas y convencionales ${ }^{23}$.

\section{IV.2.2.- Normas relativas a la producción ecológica}

\section{IV.2.2.1. Vegetal}

La fertilidad y la actividad biológica del suelo deben mantenerse o incrementarse, siguiendo un programa de rotación anual ${ }^{24}$. Esta medida puede completarse incorporando a la tierra estiércol procedente de explotaciones ganaderas ecológicas. Cuando estas medidas sean insuficientes para lugar una nutrición adecuada de los vegetales o para acondicionar la tierra y sea necesario incorporar fertilizantes orgánicos o minerales, pero únicamente los consistentes básicamente en minerales naturales poco solubles que no se obtienen mediante síntesis química.

Se evitarán al máximo la utilización de productos fitosanitarios a fin de proteger a las plantas contra los parásitos, las enfermedades y la eliminación de las malas hierbas.

La protección de los vegetales pasa, en primer lugar por una selección de especies y de variedades que sean resistentes por naturaleza; en segundo lugar, pasa por la aplicación de programas de rotación de cultivos y en último lugar por la protección de los enemigos naturales de los parásitos (conservación de setos, nidos, etc...) ${ }^{25}$.

El periodo mínimo para convertir una parcela de agricultura convencional en una agricultura ecológica es de dos años, antes de la siembra, en el caso de cultivos anuales; y de tres años, antes de la primera cosecha, en el de los cultivos vivaces distintos de las praderas. Estos periodos pueden prorrogarse o reducirse en función de la utilización anterior de las parcelas ${ }^{26}$.

En cuanto a los vegetales que crecen espontáneamente en zonas naturales y bosques, su recolección se asimila a un método de producción ecológica siempre que

\footnotetext{
${ }^{22}$ Artículo 1 del Reglamento CEE n ${ }^{\circ}$ 2092/91 del Consejo, de 24 de junio de 1991, sobre la producción ecológica y su indicación en los productos agrarios y alimentarios, DOCE L 198 de 22 de julio de 1991.

${ }^{23}$ Así ocurre con todas las normas sobre seguridad de los productos para la salud humana, artí-

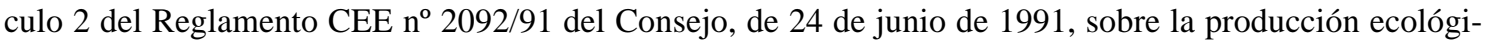
ca y su indicación en los productos agrarios y alimentarios, DOCE L 198 de 22 de julio de 1991.

${ }^{24}$ Punto 2, parte A del anexo I del Reglamento CEE n ${ }^{\circ}$ 2092/91.

${ }^{25}$ Punto 3, parte A del anexo I del Reglamento CEE $n^{\circ}$ 2092/91. Caso de que un peligro inmediato amenace al cultivo, al normativa autoriza a que se utilicen productos fitosanitarios que figuren en la lista de la parte B del anexo II del Reglamento, vg. productos a base de microorganismos.

${ }^{26}$ Punto 1 de la parte A del Anexo I del Reglamento CEE no 2092/91.
} 
cumplan dos requisitos . En primer lugar, durante los tres años anteriores, dichas zonas no se hayan tratado con productos prohibidos en la producción ecológica. En segundo lugar, la recolección no debe afectar a la estabilidad del hábitat natural ni a la supervivencia de las especies de la zona ${ }^{27}$.

\section{IV.2.2.2. Animal}

La cría ecológica de animales se orienta en el principio de un fuerte vínculo entre los animales y las fincas. Este necesario vinculo con la tierra obliga a que los animales tengan acceso a zonas de ejercicio al aire libre y asimismo a que reciban una alimentación no sólo ecológica sino preferentemente producida en la propia granja.

Los principios generales aplicables a la producción ecológica animal son básicamente $\operatorname{dos}^{28}$. El primero el principio de complementariedad entre el suelo y los animales - producción ligada al suelo- que supone la exclusión de la producción en establos de tipo cerrado -los animales deben disponer de animales al aire libre-, siendo la densidad animal por hectárea limitada. En segundo lugar se menciona el principio de separación, consistente en que todos los animales criados en una misma unidad de producción deben criarse cumpliendo las normas de la producción ecológica. Excepcionalmente es posible una producción ecológica y convencional si existen garantías suficientes que permitan evitar la confusión entre producción ecológica convencional.

Se contemplan unas normas sobre el periodo de conversión y sobre el origen de los animales. Unas se refieren a la constitución de un rebaño, seleccionando las razas que mejor se adopten al entorno y sean más resistentes a las enfermedades. Los animales procederán de una explotación que respete las normas de la agricultura ecológica y criarse posteriormente según esas normas a lo largo de toda su vida. Otras normas se refieren a la alimentación de los animales, realizándose con productos ecológicos que procedan preferentemente de la propia explotación -vg. mamíferos alimentados con leche natural-. Por último, se establecen también unos principios aplicables a la profilaxis y a los cuidados veterinarios: se da prioridad a la prevención, basada en la selección de razas apropiadas; aplicación de prácticas zootécnicas que refuercen la resistencia de animales; mantenimiento de una densidad de animales adecuada. Si estas medidas resultan insuficientes y surge una enfermedad se dará preferencia a los tratamientos naturales sobre los que tienen antibióticos que pueden dejar residuos en los productos. Los tratamientos con antibióticos se utilizarán si resultan imprescindibles para curar al animal. esta prohibido el uso de sustancias destinadas a estimular el crecimiento -vg. hormonas- o a controlar la reproducción ${ }^{29}$.

\footnotetext{
${ }^{27}$ Punto 4 de la parte A del Anexo I del Reglamento CEE n ${ }^{\circ}$ 2092/91

${ }^{28}$ Véase el punto primero de la parte B del Anexo I del Reglamento CEE no 2092/91, modificado el 19 de julio de 1999 por el Reglamento CE $n^{\circ}$ 1804/99, que establece normas mínimas para la producción ecológica animal.

${ }^{29}$ En el punto 6.1. de la parte B del anexo I del Reglamento CE n ${ }^{\circ}$ 1804/99 se establecen normas del bienestar del animal. Prácticas como el corte del rabo o el descuerne están sujetas a autorización que procederá únicamente por motivos de seguridad, higiene, salud o bienestar de los animales. Está prohibido mantener atados a los animales y las condiciones de los locales de cría y alojamiento deben responder a las necesidades fisiológicas y etológicas de los animales. El transporte de los animales debe realizarse siempre respetando el bienestar animal y de tal forma que el estrés sea mínimo.
} 


\section{IV.2.3. Normas relativas a la transformación de los productos agrícolas ecológicos en} alimentos

Se limita, sin excluirlos totalmente, los ingredientes de origen no agrario aditivos aromatizantes, agua, sal preparados a base de microorganismos-, así como los auxiliares tecnológicos que resultan imprescindibles para elaborar alimentos a partir de productos agrícolas de origen ecológico ${ }^{30}$.

Se prohíbe emplear organismos modificados genéticamente y tratamientos ionizantes, así como utilizar al mismo tiempo un ingrediente producido ecológicamente y el mismo ingrediente pero producido de manera convencional ${ }^{31}$.

\section{IV.2.4. Normas relativas al etiquetado y a la publicidad}

El etiquetado y la publicidad sólo pueden hacer referencia al método de producción ecológica si las indicaciones dejan claro que se trata de un método de producción agraria y el producto cumple las normas del Reglamento CEE 2092/91.

Ahora bien, sólo cabe hacer referencia al método de producción ecológica cuando al menos el $95 \%$ de los ingredientes han sido obtenidos por ese método. Esto es, hasta un 5\% pueden ser ingredientes producidos de forma convencional, siempre que esos productos no se encuentren en el mercado comunitario de productos ecológicos o se encuentren en cantidades insuficientes.

Los productos que tengan un porcentaje de ingredientes ecológicos de entre el 70 y el $95 \%$ sólo pueden hacer referencia a este método de producción en la lista de ingredientes no en la denominación de venta. Si fuesen menos del 70\% los ingredientes de un producto que son de origen agrícola ecológico, no se puede hacer ninguna referencia al método de producción ecológica en el etiquetado o en la publicidad del producto.

\section{IV.2.5. El logotipo de los productos agrícolas ecológicos}

En el Reglamento (CEE) no 2092/91, según la modificación efectuada en 1995 Reglamento (CE) 1935/95 del Consejo, de 22 de junio de 1995- se ofrecía a la Comisión Europea la posibilidad de aprobar un logotipo específico para la producción ecológica.

En mayo de 2000, la Comisión aprobó el logotipo específico para la producción ecológica por medio del Reglamento (CE) no $331 / 2000$ con el objetivo por una parte de dar mayor credibilidad a los productos ecológicos entre los consumidores, y por otra parte con el fin de mejorar su identificación en el mercado.

Este logotipo sin ser obligatorio, sólo lo puede llevar los productos regulados por el Reglamento (CEE) nº 2092/91 que cumplan cuatro condiciones ${ }^{32}$. La primera, tener al

\footnotetext{
${ }^{30}$ Parte B del Anexo VI del Reglamento CEE no 2092/91.

${ }^{31}$ Vide el artículo 5 del Reglamento 2092/91.

${ }^{32}$ Vide el artículo 10 del Reglamento CEE no 2092/91 y Reglamento CE no 331/2000 de la Comisión, de 17 de diciembre de 1999 - por el que se modifica el anexo V del Reglamento (CEE) $n^{\circ}$
} 
menos un $95 \%$ de ingredientes producidos según las normas de la agricultura ecológica. La segunda, haber estado sometidos al régimen de control previsto por el Reglamento durante todo el proceso de producción y de elaboración. La tercera, venderse directamente en envases sellados o comercializarse como alimentos preenvasados -en envases o contenedores- para hacer imposible sustituir su contenido; la cuarta y última es llevar en la etiqueta el nombre y/o la razón social de productor, elaborador o vendedor así como el número de código del organismo de certificación.

\section{IV.2.6. Medidas de Control}

La producción ecológica debe someterse al sistema específico de control establecido por el Estado miembro, que en todo caso ha de observar las siguientes medidas.

En primer lugar unas medidas de control de las explotaciones agropecuarias. El productor elaborará una descripción de la unidad de producción que permita identificar los lugares de producción y almacenamiento, puntos de esparcido de estiércol y lugares donde, en su caso, se efectúen operaciones de transformación y envasado. El productor notificará cada año su programa de producción vegetal, detallándolo por parcelas.

En las granjas que producen productos ecológicos de origen animal, el productor está obligado, por una lado a llevar un registro cuaderno de explotación que proporcione una versión completa del modo de gestión de los animales -llegadas y salidas de animales, por especies, las pérdidas eventuales de animales, la alimentación y los tratamientos veterinarios aplicados -; y por otra parte esta obligado a separar las parcelas y lugares de almacenamientos para la producción ecológica y para la producción convencional, cuando ambos se realicen al mismo tiempo en una explotación.

Las inspecciones de control se efectuarán "in situ” en cada explotación una vez al año como mínimo.

En segundo lugar se encuentran las medidas de control de las unidades de elaboración de alimentos a partir de productos ecológicos. El envasado y transformación de productos ecológicos deben estar separados del de productos convencionales en base al principio de separación de lugares de envasado, transformación y almacenamiento.

Por último y en tercer lugar existen normas que contemplan medidas sobre el transporte de productos ecológicos: únicamente pueden transportarse en envases o contenedores cerrados de tal forma que sea imposible sustituir el contenido.

\section{IV.3. LA PRODUCCIÓN ECOLÓGICA EN LA COMUNIDAD AUTÓNOMA DE LA RIOJA}

Según el Reglamento (CEE) 2092/91, el control de la producción agraria ecológica debe ser realizado por autoridades de control a designar por los Estados miembros. En el caso de España -como expresamente reconoce el artículo 5 del R. D. 1852/1993, de 22 de octubre, sobre producción agrícola ecológica y su indicación en los 
productos agrarios y alimenticios ${ }^{33}$-, por los órganos competentes de las Comunidades Autónomas. En este sentido, desde 1996 las Competencias de control y certificación fueron transferidas a la Comunidad Autónoma de La Rioja.

Para determinar la autoridad competente y estructurar la autoridad de control sobre esta materia dentro del ámbito de la Comunidad Autónoma de La Rioja se dicta Decreto 56/2000, de 17 de noviembre, sobre producción agrícola ecológica e indicación de la misma en los productos agrarios y alimentarios y se crea el Consejo de la Producción Agraria Ecológica de La Rioja.

IV.3.1. Decreto 56/2000, de 17 de noviembre, de la Consejería de Agricultura, Ganadería y Desarrollo Rural, sobre producción agrícola ecológica e indicación de la misma en los productos agrarios y alimentarios y se crea el Consejo de Producción Agraria Ecológica de la Rioja

En el Decreto 56/2000 se regula en primer lugar la producción, la elaboración y la comercialización de productos ecológicos, esto es, productos agrícolas vegetales no transformados, productos animales y productos animales sin transformar en la medida en que se adecuen a lo dispuesto en los anexos I y III del Reglamento CEE 2091/91; productos agrícolas vegetales transformados y productos animales transformados destinados a la alimentación humana, preparados básicamente a partir de uno o más ingredientes de origen vegetal o animal; y por último, alimentos para animales, piensos compuestos y materias primas para la alimentación animal no recogidos en el párrafo a) en las condiciones establecidas ${ }^{34}$ por el Reglamento (CE) 1804/1999.

En segundo lugar el Decreto 56/2000, se ocupa de los instrumentos de fermento, promoción, control y asesoramiento en materia de actividad agraria ecológica. Los productos ecológicos se distinguirán del resto con la aparición en las etiquetas, la publicidad o en los alimentos animales de las palabras ecológico, biológico y "orgánico" o de los prefijos "bio" y "eco" 35 . Para no inducir a confusión al consumidor, se prohibe la utilización de estas denominaciones en los alimentos que no hayan sido producidos con métodos ecológicos ${ }^{36}$.

Las funciones de la autoridad de control, "órgano de control de la Agricultura Ecológica de La Rioja”, se ejercerá por la Dirección General de Desarrollo Rural ${ }^{37}$. Se crea el Consejo de la producción agraria ecológica de La Rioja, para ejercer las funciones de consulta y colaboración en materia de agricultura ecológica ${ }^{38}$. Da normas

\footnotetext{
${ }^{33}$ Recientemente por Real Decreto 506/2001, de 11 de mayo se ha modificado el Real Decreto 1852/1993, de 22 de octubre, sobre producción agrícola ecológica y su indicación en los productos agrarios y alimenticios, BOE de 26 de mayo de 2001, no 126.

${ }^{34}$ Vide el artículo único punto 1 del RD 506/2001, de 11 de mayo por el que se modifica el RD 1852/1993, de 22 de octubre sobre producción agrícola ecológica y su indicación en los productos agrarios y alimentarios. Vide también el artículo 1 del Decreto 56/2000, de 17 de noviembre, de La Rioja.

${ }^{35}$ Vide el artículo 2.1 del Decreto 56/2000 de La Rioja.

${ }^{36}$ Vide el artículo 2.2 del Decreto 56/2000 de La Rioja.

${ }^{37}$ Vide el artículo 4 del Decreto 56/2000 de La Rioja.

${ }^{38}$ Vide el artículo 5 del Decreto 56/2000 de La Rioja; en su artículo 12 describe sus competencias, en el artículo 13 sus funciones, en el artículo 14 su composición, en el 15 el régimen de las sesiones y en el artículo 16 se ocupa del presidente del consejo.
} 
técnicas de producción y elaboración ${ }^{39}$ y se establecen las obligaciones de los operadores $^{40}$ de notificar la actividad a la Consejería, someterse a los controles necesarios y cumplir las normas técnicas referentes a la naturaleza de los productos, de las fincas, métodos de producción y elaboración previsto, al uso de determinados fertilizantes, agentes antiparasitarios y fármacos.

Se crean los registros de operadores ${ }^{41}$. Se establece un sistema de control ${ }^{42}$.Los controles se realizarán de forma periódica y para ello los operadores de agricultura ecológica facilitarán las facturas y justificantes necesarios, las muestras que se requieran y el acceso a las instalaciones.

En cuanto a la indicación de conformidad ${ }^{43}$. Los productos agrarios y alimentarios ecológicos llevarán una contraetiqueta numerada con el logotipo y en la que figuran las inscripciones "La Rioja" y "ES-RI-AE", Organo de control de la Agricultura Ecológica" y además del número y la serie.

\section{IV.3. 2. La agricultura y ganadería ecológica de La Rioja en cifras}

Los operadores productores ecológicos en la comunidad autónoma de La Rioja a primeros del año 2000 eran cuarenta y cinco de producción agrícola - 1041 hectáreas cultivadas-, uno de productos silvestres - 300 hectáreas- y cinco ganaderos - 1237 colmenas y 207 cabras- y un productor de compost.

En cuanto a los productos de la agricultura ecológica de La Rioja, los treinta operadores se distribuyen así: trece operadores, elaboradores, envasadores y comercializadores de vino de D.O. calificada Rioja -son vinos de calidad, buen grado y color, una correcta acidez fija y elevados aromas frutales-; tres destiladores de orujo (aguardientes) de uva cultivada con técnicas ecológicas; una vinagrería; un operador de frutas y hortalizas frescas- el envasado es de frutas (peral y manzano) y hortalizas (pimientos, alcachofas); un operador que comercializa frutos secos; dos operadores de conservas vegetales; dos de elaboración y envasado de aceite de oliva virgen extra; uno de queserías de leche de cabra que pastan en libertad la flora espontánea de la sierra; uno de panadería; dos silvestres, medicinales y aromáticas -en áreas de montaña se producen plantas medicinales para la salud humana, y se recolectan manualmente, se deshidratan para obtener sus esencias naturales-; y por último tres de envasado de miel producidos en colmenares situados en zonas de montaña, extrayéndose por métodos físicos y envasándose después de un proceso de decantación y filtrado. La producción es preferentemente miel uniflora: brezo, romero, etc.-.

\footnotetext{
${ }^{39}$ Vide el artículos 6 y 7 del Decreto 56/2000 de La Rioja.

${ }^{40}$ Vide el artículos 8 y 10 del Decreto 56/2000 de La Rioja.

${ }^{41}$ Vide el artículo 9 del Decreto 56/2000 de La Rioja.

${ }^{42}$ Vide el artículo 10 del Decreto 56/2000 de La Rioja.

${ }^{43}$ Vide el artículo 11 del Decreto 56/2000 de La Rioja.
} 